\title{
Avaliação hematológica de éguas gestantes infectadas por Theileria equi e suplementadas com vitamina E nas dietas*
}

\section{Hematological evaluation of pregnant mares infected by Theileria equi and supplemented with vitamin $\mathrm{E}$ diets}

\author{
Cristiana Portz; ${ }^{*}$ Fernando Queiroz de Almeida; ${ }^{* * *}$ Carlos Luiz Massard;**** Paula Vieira Evans Hossell Laranjeira ${ }^{* *}$
}

\begin{abstract}
Resumo
Este estudo foi conduzido na Universidade Federal Rural do Rio de Janeiro utilizando éguas gestantes das raças Mangalarga Marchador e Bretão Postier provenientes de local endêmico para a babesiose eqüina. O objetivo deste trabalho foi avaliar a resposta dos parâmetros hematológicos e imunológicos em eqüinos infectados por Theileria equi e alimentados com dieta suplementada com vitamina E. Foram utilizadas oito éguas Mangalarga Marchador e quatro éguas Bretão Postier com dietas suplementadas $80 \mathrm{mg}$ vitamina E/100kg peso vivo, durante 30 dias até o parto. As alterações hematológicas observadas nas éguas não foram significativas, considerando-se os casos crônicos de babesiose. Houve predominância de leucocitose e linfocitose, sem diminuição do VGM nos potros de ambas as raças, cujas éguas foram suplementadas com vitamina $\mathrm{E}$. A suplementação dietética de vitamina $E$ não foi suficiente para modular a resposta imune nas éguas e potros nascidos de éguas das raças Mangalarga Marchador e Bretão Postier alimentadas com dietas suplementadas com vitamina E.
\end{abstract}

Palavras-chave: babesiose eqüina, imunomodulação, vitamina $\mathrm{E}$.

\begin{abstract}
This study was carried out at Universidade Federal Rural do Rio de Janeiro with pregnant mares and foals of Mangalarga Marchador and Bretão Postier breeds living at an endemic area to equine babesiosis. This study aims to evaluate hematological and immunological parameters in horses infected by Theileria equi with supplemented diets with vitamin E. Eight Mangalarga Marchador and four Bretão Postier mares with diets supplemented with $80 \mathrm{mg}$ vitamin E/100Kg body weight/day during thirty days until parturation. Hematological alterations in mares were not important to chronic babesiosis in horses. WBC values from foals of Mangalarga Marchador and Bretão Postier mares with supplemented diets demonstrated leukocytosis and increase in relative and absolute values of lymphocytes, without decrease of the MCV.
\end{abstract}

Keywords: equine babesiosis, immunomodulation, vitamin $\mathrm{E}$.

\section{Introdução}

O plantel eqüino da Universidade Federal Rural do Rio de Janeiro apresenta-se endêmico para as duas espécies causadoras de babesiose devido a constante reinfecção através dos carrapatos vetores de acordo com Pfeifer Barbosa et al. (1995). Segundo Cunha et al. (1998), os animais infectados por Theileria equi tornam-se geralmente portadores crônicos e fontes de infecção por longos períodos.

$\mathrm{Na}$ espécie eqüina, a placenta do tipo epiteliocorial impede a passagem de anticorpos da circulação materna para a fetal, fazendo com que suas progênies nasçam com ausência ou níveis insignificantes de anticorpos. A IgG é a principal imunoglobulina presente no colostro das éguas, sendo mobilizadas do sangue materno para a glândula mamária (Jeffcott, 1972).
Em geral, parasitos como Babesia sp., Theileria sp. e Plasmodium sp. invadem os eritrócitos dos animais infectados gerando dano celular oxidativo induzido pela multiplicação do parasito (Murase et al., 1996; Otsuka et al., 2002). Na infecção aguda por Babesia sp. ocorrem mudanças bioquímicas celulares, como a oxidação lipídica na membrana dos eritrócitos parasitados (Ambawat et al. 1999). A vitamina $E(\alpha-$ tocoferol) age como protetor de membrana celular, antioxidante biológico, possuindo ainda mecanismo modulador da resposta imune dos animais, protegendo os leucócitos e macrófagos durante a fagocitose (McDowell, 1989). Bekyarova et al. (1996) reportaram que a vitamina $E$ reduz a deformidade dos eritrócitos devido a sua capacidade antioxidante.

Em bovinos suplementados com $\alpha$-tocoferol observou-se aumento da mitose de linfócitos T e B (Reddy et al., 1987),

* Parte da dissertação de mestrado no Curso de Mestrado em Ciências Veterinárias da UFRRJ, parcialmente financiada com recursos do Programa PROCAD/CAPES

** Médico-veterinário. Curso de Pós-Graduação em Ciências Veterinárias UFRRJ. Bolsista da CAPES

*** Professor associado. Instituto de Veterinária. UFRRJ. Bolsista Pesquisador CNPq. falmeida@ufrrj.br

${ }^{* * * *}$ Professor titular. Instituto de Veterinária. UFRRJ. Bolsista Pesquisador CNPq. carlosmassard@ufrrj.br 
enquanto a utilização de vitamina $E$ associada ao selênio e aplicada em ovinos portadores de Brucella ovis resultou em aumento de anticorpos antibrucela (Afzal et al. 1984).

A forma de vitamina $E$ mais encontrada nos tecidos dos eqüinos é o $\alpha$-tocoferol, sendo também encontrado em forrageiras frescas e verdes e cereais, sendo necessária a suplementação dietética com acetado de $\alpha$-tocoferol (Frape, 1998). As taxas de absorção dos tocoferóis e tocotrienóis são, em geral, relativas às suas potências biológicas antioxidantes. O tocoferol atravessa a glândula mamária, e assim, a dieta da égua influencia na reserva de vitamina $E$ do potro ao nascimento através do colostro materno (McDowell, 1989).

Segundo Hoffman et al. (1999), há um aumento significativo na concentração de $\lg G$ no soro de éguas gestantes suplementadas com 160 UI vitamina $E / \mathrm{kg} / \mathrm{dia}$, com conseqüente aumento da concentração de $\lg G$ nos soros dos potros nascidos dessas éguas. O uso de imunomoduladores, portanto, poderia aumentar o desempenho de éguas portadoras de infecção crônica por babesiose, incrementando a resposta hematológica e imune de éguas e potros lactentes.

O objetivo deste trabalho foi avaliar a resposta dos parâmetros hematológicos de éguas gestantes infectadas por Theileria equi com dieta suplementada com vitamina $\mathrm{E}$.

\section{Material e métodos}

O experimento realizou-se na Universidade Federal Rural do Rio de Janeiro, Seropédica, RJ, utilizando éguas gestantes das raças Mangalarga Marchador e Bretão Postier do Setor de Eqüinocultura do Instituto de Zootecnia, no período de agosto de 2001 a julho de 2002. Foram utilizadas oito éguas da raça Mangalarga Marchador e quatro éguas da raça Bretão Postier e mantidas separadas dos bovinos. No terço final da gestação e durante a lactação, as éguas receberam ração concentrada, sendo mantidas em pastagens de capimcolonião durante o dia e, à noite, mantidas em piquetes para observação do parto.

A estação de parição das éguas ocorreu no período de agosto de 2001 a junho de 2002, coincidindo com a época de altas infestações nas pastagens de larvas, ninfas e adultos de ixodídeos, propiciando a infestação dos potros nos primeiros dias de vida. Durante o período experimental, foram colhidos carrapatos dos animais para identificação, observando-se a presença de Amblyomma cajennense e Anocentor nitens, e ausência de Boophilus microplus. Segundo Pfeifer Barbosa et al. (1995), com o aumento da população de larvas e ninfas no inverno, a transmissão de $T$. equi ocorre na primavera e verão, na fase adulta, portanto a alta infestação de carrapatos nos eqüinos justifica a denominação de área endêmica para a babesiose eqüina, no plantel da UFRRJ.

As éguas foram distribuídas em três tratamentos descritos a seguir: Tratamento I (grupo controle): quatro éguas da raça Mangalarga Marchador, mantidas em pastos de capimcolonião, e suplementadas com ração concentrada em quantidades equivalentes a $0,5 \%$ do peso vivo, durante 30 dias pré-parto; Tratamento II (Vit E-MM): quatro éguas da raça Mangalarga Marchador consumindo dieta semelhante à do grupo controle, com adição diária na dieta de $80 \mathrm{mg}$ de vitamina $\mathrm{E} / 100 \mathrm{~kg}$ de peso vivo, durante 30 dias pré-parto. Tratamento III (Vit E-BP): quatro éguas da raça Bretão Postier, consumindo dieta semelhante à do grupo controle, com adição diária na dieta de $80 \mathrm{mg}$ de vitamina E/100kg de peso vivo, durante 30 dias pré-parto. A vitamina $E$, em pó foi cedida pela $\mathrm{ROCHE}^{\circledR}$, pesada individualmente para cada animal e oferecida juntamente com a ração, pela manhã, uma vez ao dia. A quantidade de Vitamina $\mathrm{E}$ foi estimada pela conversão de $1 \mathrm{UI}$ de acetado de $\alpha$-tocoferol equivalente a $1,0 \mathrm{mg}$ de vitamina $\mathrm{E}$.

As coletas de sangue das éguas foram realizadas duas semanas antes do início da suplementação com vitamina $E$ até duas semanas após o parto, em intervalos de sete dias, obtidas por colheita de $5 \mathrm{~mL}$ de sangue da veia jugular em tubos siliconizados com gel retrator de coágulo. Nos potros, as coletas de sangue foram realizadas após o parto e a cada duas semanas até a $11^{\text {a }}$ semana pós-parto. Após a coagulação do sangue, os soros foram separados, e mantidos a $-20^{\circ} \mathrm{C}$, até serem submetidos à técnica de ELISA indireto para a detecção de anticorpos específicos para $T$. equi.

A avaliação hematológica dos animais realizou-se em até 12 horas após colheita de $3 \mathrm{ml}$ de sangue da veia jugular, procedida em tubos com anticoagulante EDTA. A análise hematológica seguiu o protocolo de Navarro e Pachaly (1994), e as concentrações de proteína total e fibrinogênio foram determinadas por refratometria, segundo metodologia descrita por Coles (1974).

Para a realização do ELISA indireto foi desenvolvido um ensaio imunoenzimático para a detecção de anticorpos para T. equi segundo metodologia e padronização descrita por Botteon (2003). A concentração ótima do antígeno, cedido gentilmente pela UNESP-Jaboticabal, de $T$. equi foi de $10 \mathrm{~g} / \mathrm{mL}$ de tampão

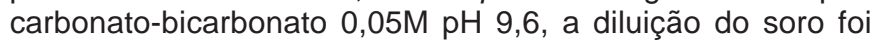
estabelecida em 1:100 e a do conjugado 1:1000. Como branco, empregou-se a leitura dos orifícios contendo todos os elementos da reação, com exceção do soro eqüino. Considerou-se como positivo as reações que apresentaram densidade óptica maior que as médias dos controles negativos acrescidas de dois desvios-padrão. A leitura da reação foi realizada em espectrofotômetro para ELISA Labsistems IEMS Reader MF, com filtro de $405 \mathrm{~nm}$, utilizando a microplaca Nunclon Surface. O tempo de leitura das placas do ELISA indireto foi estabelecido em 40 minutos, como o menor tempo necessário para uma boa diferenciação entre os controles positivos e negativos, sem permitir leitura significativa no branco da reação. A determinação do índice de ELISA (IE) foi elaborada segundo descrição de Botteon (2003).

Foi utilizado um delineamento inteiramente casualizado com três tratamentos em arranjo de parcelas subdivididas, onde os tratamentos foram analisados nas parcelas e o tempo, em semanas, nas subparcelas. Os resultados obtidos foram submetidos à análise de variância e os valores médios comparados pelo teste de Tukey, a $5 \%$ de probabilidade. Os resultados hematológicos das éguas e potros, avaliados em função das semanas, foram submetidos à análise de regressão, adotando o nível de significância de $1 \%$ de probabilidade, utilizando o programa Sistema de Análises Estatísticas e Genéticas - SAEG (UFV, 2000).

\section{Resultados e discussão}

Os índices de ELISA (IE), que variam de 0 a 9 de acordo com a intensidade da resposta, foram classificados nos quatro 
grupos descritos a seguir: grupo 1 -IE de zero, significando ausência de anticorpos; Grupo 2 IE de 1 a 3, significando soros fracamente positivos; Grupo 3 - IE de 4 a 6, significando soros de média positividade e Grupo 4 - IE de 7 a 9, significando soros fortemente positivos. Na Figura 1, estão demonstrados os valores médios dos índices de ELISA classificados nas éguas.

Não foram observados efeitos significativos da suplementação dietética com vitamina $E$ nas éguas das raças Mangalarga Marchador e Bretão Postier e o período experimental nos IE das éguas do experimento. Observaram-se títulos de anticorpos fracamente positivos, com IE igual a 1 , nas éguas de ambas as raças, permitindo inferir que o parto parece não ter contribuído como fator de estresse para a redução do nível de anticorpos; portanto, não se verificou efeito significativo da vitamina $E$ na resposta humoral das éguas. O ELISA classificado como fracamente positivo, com IE igual a 2, nas éguas da raça Bretão Postier pode ser justificado pela ocorrência clínica da $T$. equi em uma das éguas da raça Bretão Postier, alterando os valores médios do grupo experimental.

Os resultados sorológicos indicam uma estabilidade enzoótica devido ao título baixo de anticorpos e a constante reinfecção das éguas no Setor de Eqüinocultura da UFRRJ e concordam com Pfeifer Barbosa et al. (1995), que relataram $100 \%$ de positividade para $T$. equi em soros de eqüinos da UFRRJ.

Em relação aos potros lactentes destas éguas, os valores médios dos índices de ELISA não diferiram significativamente em função da suplementação com vitamina E nas dietas das éguas das raças Mangalarga Marchador e Bretão Postier, porém apresentaram diferenças significativas $(P<0,05)$ em função da idade do potro, expressas em semanas (Portz et al., 2007), com aumento de anticorpos após a primeira semana de idade, devido aos anticorpos passivos adquiridos; posteriormente, houve uma tendência de redução com nova elevação a partir da sétima semana nos potros nascidos de éguas de ambas as raças cujas dietas foram suplementadas com vitamina $\mathrm{E}$.

Esta elevação pode estar relacionada com resposta ativa dos potros após infecção natural por T. equi, pois em alguns potros observou-se a infestação pelos carrapatos $A$. cajennense $e$ $A$. nitens fixados na conjuntiva e ao redor do ânus, no primeiro dia de vida (Portz et al., 2007). Os resultados obtidos são concordantes com os observados por Shein (1988), que relata a primo-infecção moderada em potros de áreas endêmicas.

$\mathrm{Na}$ Tabela 1 podem ser observados os valores médios da hematimetria, do hematócrito, da concentração de hemoglobina e do fibrinogênio em éguas de ambas as raças, alimentadas com dietas suplementadas com vitamina E. Não foram observados efeitos significativos da suplementação de vitamina $E$ nas dietas das éguas e do tempo do período experimental. Estes valores estão dentro dos limites normais para eqüinos adultos, do tipo linfático, para hematimetria, de 5,5 a $9,5 \times 10^{6} / \mu \mathrm{L}$, para hematócrito, de 24 a $44 \%$, para hemoglobina, de 8 a $14 \mathrm{~g} / \mathrm{dL}$ e para fibrinogênio, de 0,2 a 0,6g/ dL, descritos por Navarro e Pachaly (1994).

Os valores médios do volume globular médio (VGM) e da concentração da hemoglobina globular média (CHGM) apresentaram diferenças significativas entre as éguas das raças Mangalarga Marchador e Bretão Postier alimentadas com dietas suplementadas com vitamina $\mathrm{E}$. O valor médio do VGM nas éguas do grupo controle, de 44,8/fL não diferiu ( $p>0,05)$ do valor observado nas éguas da raça Mangalarga Marchador alimentadas com dietas suplementadas com vitamina $E$, de 46,5/fL. Entretanto, considerando os valores médios do VGM das éguas alimentadas com dietas suplementadas com vitamina $\mathrm{E}$, as éguas da raça Bretão Postier apresentaram valor significativamente inferior, de 40,9/ $\mathrm{fL}$, o que pode estar relacionado com diferenças raciais.

Os valores médios da CHGM nas éguas da raça Mangalarga Marchador não diferiram $(p>0,05)$, independentemente da suplementação com vitamina $E$ que foram de 30,7 e de $30,3 \%$, para as éguas do grupo controle e éguas da raça Mangalarga Marchador suplementadas. Considerando as éguas da raça Bretão Postier, a suplementação da dieta com vitamina $\mathrm{E}$ aumentou significativamente o $\mathrm{CHGM}$, observando o valor de $31,3 \%$. Os valores médios do CHGM nas éguas da raça Mangalarga Marchador e Bretão Postier estão dentro do limite de normalidade, de 31,0 a $38,5 \%$, descritos por Navarro e Pachaly (1994). Observou-se efeito significativo do período experimental nos valores médios do VGM e proteína plasmática total nas éguas das raças Mangalarga Marchador e Bretão Postier alimentadas com dietas suplementadas com vitamina $\mathrm{E}$, que podem ser observados na Tabela 2.

Observou-se resposta linear positiva $(p<0,01)$ dos valores médios do VGM em função das semanas do período experimental, com valores variando de 40,3 a 51,9/fL, enquanto os valores médios da proteína plasmática total em função das semanas apresentaram resposta quadrática $(p<0,01)$.

Os resultados dos parâmetros hematológicos não permitem concluir que houve alteração significativa entre as éguas das raças Mangalarga Marchador e Bretão Postier alimentadas com dietas suplementadas com vitamina E. Observou-se um aumento linear no decorrer das semanas, do VGM, sugerindo um processo de regeneração celular. Rudolph et al. (1975) observaram redução do VGM, relacionando este fato com a 
Tabela 2: Médias e equações de regressão (ER) do volume globular médio (VGM) e proteína plasmática total (PT) em função das semanas experimentais em éguas das raças Mangalarga Marchador (MM) e Bretão Postier (BP) alimentadas com dietas suplementadas com vitamina $\mathrm{E}$

\begin{tabular}{|c|c|c|c|c|c|c|c|c|c|}
\hline \multirow{2}{*}{ Variáveis } & \multicolumn{6}{|c|}{ Semanas } & \multirow{2}{*}{ ER } & \multirow{2}{*}{$\begin{array}{l}\text { CV } \\
(\%)\end{array}$} & \multirow{2}{*}{$\begin{array}{c}\text { Valores } \\
\text { normais }\end{array}$} \\
\hline & 1 & 2 & 3 & 4 & 5 & 6 & & & \\
\hline VGM (fL) & 40,3 & 42,1 & 45,7 & 46,2 & 49,4 & 51,9 & 1 & 20,2 & 37 a 58,5 \\
\hline PT $(\mathrm{g} / \mathrm{dL})$ & 8,1 & 8.0 & 8,2 & 8,2 & 8.0 & 7.2 & 2 & 6.3 & 5.8 a 8.7 \\
\hline
\end{tabular}

${ }^{1} v=37,8+2,32 X, r^{2}=14,7(P<0,01) ;{ }^{2} v=75,9+5,11 X-9,10 X^{2}, r^{2}=22,9(p<0,01)$, onde $X$ significa semanas

* NAVARRO e PACHALY (1994).

Tabela 3: Valores médios do leucograma em éguas das raças Mangalarga Marchador (MM) e Bretão Postier (BP) alimentadas com dietas suplementadas com vitamina $\mathrm{E}$

\begin{tabular}{|c|c|c|c|c|c|c|}
\hline \multirow{3}{*}{ Variáveis } & \multicolumn{3}{|c|}{ Tratamentos } & \multirow{3}{*}{ Média } & \multirow{3}{*}{$\begin{array}{l}\text { CV } \\
(\%)\end{array}$} & \multirow{3}{*}{$\begin{array}{l}\text { Valores } \\
\text { normais }\end{array}$} \\
\hline & Controle & Vit E & Vit E & & & \\
\hline & MM & $\mathrm{MM}$ & $\mathrm{BP}$ & & & \\
\hline \multicolumn{7}{|c|}{ Leucograma } \\
\hline MON $(\mu \mathrm{L})$ & $1621,0^{a}$ & $1651,0 a$ & $1694,0 a$ & 1656,0 & 71,1 & 0 a 1000 \\
\hline $\operatorname{EOS}(\mu \mathrm{L})$ & $1025,0^{a}$ & $852,0 a$ & $578,0 a$ & 818,0 & 93,5 & 0 a 1000 \\
\hline BAS $(\mu \mathrm{L})$ & $107,5^{\mathrm{a}}$ & $85,4 a$ & $194,8 a$ & 129,2 & 122,53 & raros \\
\hline
\end{tabular}

MON = monócitos; EOS = eosinófilos; BAS = basófilos

Médias seguidas de letras iguais na linha, para cada variável, não diferem entre si pelo teste de Tukey $(P<0,05)$

*NAVARRO e PACHALY (1994).

fagocitose de eritrócitos normais e parasitados, na fase aguda da $T$. equi, discordando dos resultados observados neste experimento, onde houve um aumento linear do VGM no decorrer das semanas do período experimental. Os resultados obtidos no presente experimento são concordantes com as observações de Cunha et al. (1998), relatando que na fase crônica da infecção por Babesia sp, não houve alterações significativas no hematócrito de eqüinos.

Os valores médios dos monócitos, eosinófilos e basófilos nas éguas das raças Mangalarga Marchador e Bretão Postier alimentadas com dietas suplementadas com vitamina $E$ podem ser vistos na Tabela 3. Não foram observados efeitos significativos da suplementação de vitamina $E$ nas dietas das éguas e do tempo do período experimental. Os valores médios estão dentro dos limites normais para eqüinos adultos, do tipo linfático, segundo Navarro e Pachaly (1994). Em relação aos valores médios dos monócitos observa-se que, independentemente da suplementação de vitamina E, as éguas apresentaram valores acima dos limites normais, de zero a 1000/fL, descritos por Navarro e Pachaly (1994). Tal fato foi descrito por Rudolph et al. (1975), quando observaram monocitose em resposta a infecções por $T$. equi em eqüinos adultos da raça PSI. A fagocitose dos parasitos por monócitos e neutrófilos é um fenômeno biológico comum. Portanto, há aumento esperado de células fagocitárias em doenças causadas por protozoários.

Observou-se interação significativa dos trata-mentos e período experimental para os valores médios dos leucócitos totais, linfócitos e neutrófilos nas éguas das raças Mangalarga Marchador e Bretão Postier alimentadas com dietas suplementadas com vitamina $E$ (Tabela 4).

Em relação aos leucócitos totais, observou-se que, independentemente dos tratamentos, os valores médios variam de 11116 a $12912 / \mathrm{il}$, indicando a ocorrência de leucocitose nas éguas das raças Mangalarga Marchador e Bretão Postier alimentadas com dietas suplementadas com vitamina $\mathrm{E}$. Os valores médios dos neutrófilos, independentemente dos tratamentos, variaram de 5736 a 6849/fL, indicando pouca alteração nesta variável nas éguas das raças Mangalarga Marchador e Bretão Postier alimentadas com dietas suplementadas com vitamina $\mathrm{E}$, e que estão dentro dos limites normais, de 2300 a 8500/fL, segundo Navarro e Pachaly (1994).

$\mathrm{Na}$ Tabela 5 podem ser observados os valores médios da hematimetria, hematócrito, da concentração de hemoglobina, da concentração de proteína plasmática e do fibrinogênio dos potros nascidos das éguas das raças Mangalarga Marchador e Bretão Postier cujas dietas foram suplementadas com vitamina E. Observou-se efeito significativo da idade dos potros, expressas em semanas, nos valores médios da hematimetria, hematócrito, hemoglobina, proteína plasmática total e fibrinogênio.

Em relação aos valores médios das concentrações da proteína plasmática total e fibrinogênio, observou-se resposta linear positiva $(p<0,01)$ em função da idade dos potros. Os valores de fibrinogênio apresentaram oscilações durante as primeiras semanas de idade, podendo ser um indicativo da ocorrência da babesiose ou de um processo inflamatório em andamento (Rudolph et al.,1975).

$\mathrm{Na}$ Tabela 6 , podem ser observados os valores médios do VGM dos potros nascidos das éguas das raças Mangalarga Marchador e Bretão Postier, cujas dietas foram suplementadas com vitamina E. Não foram observados efeitos significativos da suplementação de vitamina $E$ nas dietas das éguas e da idade dos potros no VGM.

Observou-se interação significativa da suplementação dietética com vitamina $E$ das éguas com a idade dos potros para os valores médios da CHGM nos potros das raças Mangalarga Marchador e Bretão Postier que podem ser observados na Tabela 7. Ribeiro et al. (1995) relatam decréscimo do VGM em potros de área endêmica, não observado neste experimento, sugerindo uma resposta passiva à administração de vitamina $E$ nas éguas.

Os valores médios dos leucócitos totais, linfócitos, eosinófilos e basófilos dos potros nascidos das éguas das raças Mangalarga Marchador e Bretão Postier cujas dietas foram suplementadas com vitamina $\mathrm{E}$ podem ser observados na Tabela 8. Os valores médios dos leucócitos totais e linfócitos foram maiores nos potros das éguas das raças Mangalarga Marchador e Bretão Postier cujas dietas foram suplementadas com vitamina $E$, de 11314,5 e $11472,5 / \mu \mathrm{L}$; e de 3479,0 e $2683,9 / \mathrm{fL}$, 
Tabela 4: Médias e equações de regressão (ER) do leucograma em função da interação entre semanas experimentais e tratamentos em éguas das raças Mangalarga Marchador (MM) e Bretão Postier (BP) alimentadas com dietas suplementadas com vitamina $\mathrm{E}$

\begin{tabular}{|c|c|c|c|c|c|c|c|c|c|}
\hline \multirow{2}{*}{ Tratamento } & \multicolumn{6}{|c|}{ Semanas } & \multirow{2}{*}{ ER } & \multirow{2}{*}{$\begin{array}{l}\text { CV } \\
(\%)\end{array}$} & \multirow{2}{*}{$\begin{array}{l}\text { Valores } \\
\text { normais* }\end{array}$} \\
\hline & 1 & 2 & 3 & 4 & 5 & 6 & & & \\
\hline \multicolumn{10}{|c|}{ 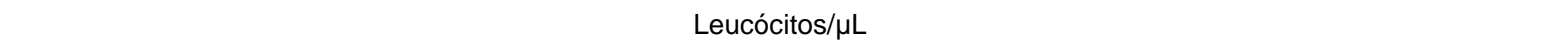 } \\
\hline Controle & $15550 a$ & $13062 a$ & $9255 b$ & $15050 a$ & $12287 a$ & $9887 a b$ & 12515 & & \multirow{3}{*}{$\begin{array}{c}6000 \mathrm{a} \\
12000\end{array}$} \\
\hline Vit E -MM & $13875 a$ & $12800 a$ & 15412ab & 10737ab & 10875ab & $13775 a$ & 12912 & 24,2 & \\
\hline Vit E -BP & 10820a & $10775 a$ & $12350 a b$ & $11587 a b$ & $9625 a b$ & 11537ab & 11116 & & \\
\hline \multicolumn{10}{|c|}{ Linfócitos/ $\mu \mathrm{L}$} \\
\hline Controle & $4717 a$ & $2773 a$ & $2479 b$ & $3958 a$ & $2385 a$ & $2488 b$ & 1 & \multirow{3}{*}{30,6} & \multirow{3}{*}{1500 a 7700} \\
\hline Vit E -MM & $3243 a$ & $3553 a$ & $4744 a$ & $2952 a$ & $4093 a$ & $4368 a b$ & 3826 & & \\
\hline Vit E -BP & $3100 a$ & $2947 a$ & $2836 b$ & $3100 a$ & $2550 a$ & $3317 a b$ & 2975 & & \\
\hline \multicolumn{10}{|c|}{ Neutrófilos/ $\mu \mathrm{L}$} \\
\hline Controle & $8531 a$ & $7946 a$ & $4929 b$ & $7532 a$ & $7134 a$ & $5024 a b$ & 6849 & \multirow{3}{*}{27,5} & \multirow{3}{*}{2300 a 8500} \\
\hline Vit E -MM & $7063 a$ & $6648 a$ & $8677 a b$ & $5669 a b$ & $5096 a b$ & $7612 a$ & 6794 & & \\
\hline Vit E -BP & $5501 a$ & $5581 a$ & $6481 a b$ & $6089 a b$ & $5159 a b$ & $5602 a b$ & 5736 & & \\
\hline
\end{tabular}

${ }^{1} \mathrm{~V}=42,1-3,09 X, \mathrm{r}^{2}=13,8(\mathrm{P}<0,01)$; onde $\mathrm{X}$ significa semanas

Médias seguidas de letras diferentes, na coluna, para cada variável em cada semana, diferem entre si pelo teste de Tukey $(p<0,05)$ *NAVARRO e PACHALY (1994).

Tabela 5: Médias e equações de regressão (ER) da hematologia em função das semanas de idade dos potros das raças Mangalarga Marchador (MM) e Bretão Postier (BP)

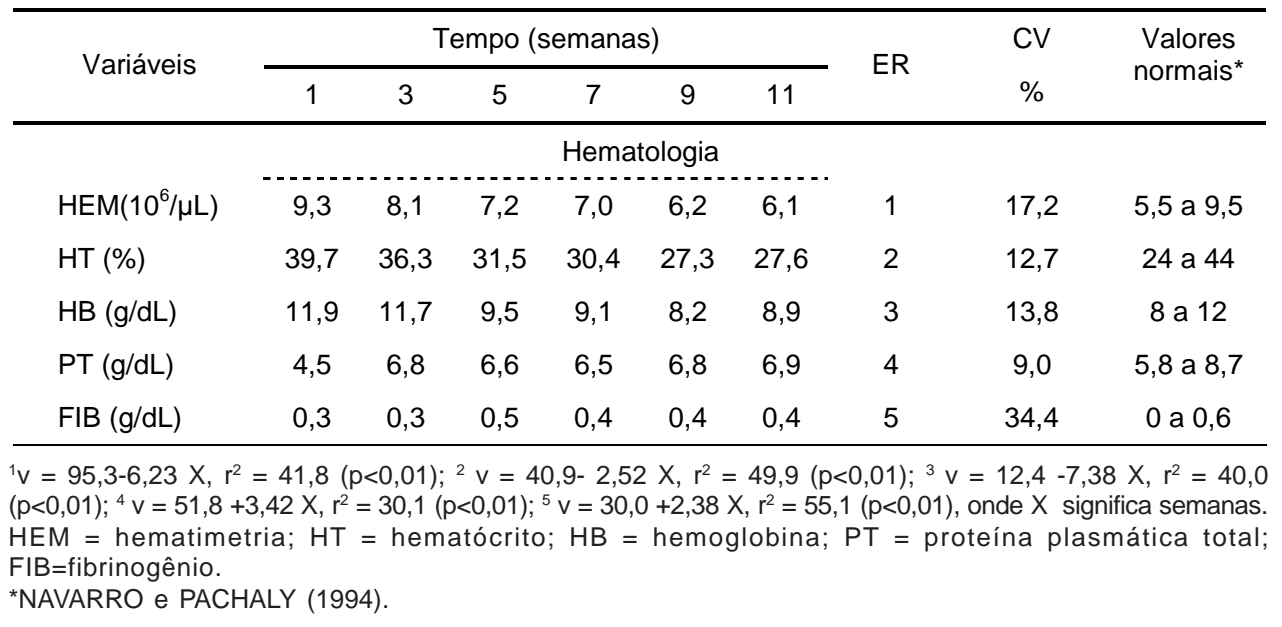

Tabela 6: Valores médios do volume globular médio (VGM) em potros nascidos das éguas das raças Mangalarga Marchador e Bretão Postier cujas dietas foram suplementadas com vitamina $\mathrm{E}$

\begin{tabular}{|c|c|c|c|c|c|c|}
\hline \multirow[b]{2}{*}{ Variáveis } & \multicolumn{3}{|c|}{ Tratamentos } & \multirow[b]{2}{*}{ Média } & \multirow{2}{*}{$\begin{array}{l}\text { CV } \\
(\%)\end{array}$} & \multirow{2}{*}{$\begin{array}{l}\text { Valores } \\
\text { normais* }\end{array}$} \\
\hline & $\begin{array}{c}\text { Controle } \\
\text { MM }\end{array}$ & $\begin{array}{l}\text { Vit E } \\
\text { MM }\end{array}$ & $\begin{array}{l}\text { Vit E } \\
\text { BP }\end{array}$ & & & \\
\hline \multicolumn{7}{|c|}{ Hematologia } \\
\hline VGM (fL) & $45,9 a$ & $45,6 a$ & $44,4 a$ & 45,3 & 16,8 & 37 a 58,5 \\
\hline
\end{tabular}

Médias seguidas de letras iguais na linha não diferem entre si pelo teste de Tukey $(p<0,05)$ *NAVARRO e PACHALY (1994 
Tabela 7: Valores médios da concentração de hemoglobina globular média (CHGM) em função da interação da suplementação de vitamina $E$ nas dietas das éguas com a idade dos potros das raças Mangalarga Marchador (MM) e Bretão Postier (BP)

\begin{tabular}{|c|c|c|c|c|c|c|c|c|c|}
\hline \multirow{2}{*}{ Tratamento } & \multicolumn{6}{|c|}{ Tempo (semanas) } & \multirow[t]{2}{*}{ Médias } & \multirow{2}{*}{$\begin{array}{l}\text { CV } \\
(\%)\end{array}$} & \multirow[t]{2}{*}{$\begin{array}{c}\text { Valores } \\
\text { normais* }\end{array}$} \\
\hline & 1 & 3 & 5 & 7 & 9 & 11 & & & \\
\hline \multicolumn{10}{|c|}{ CHGM (\%) } \\
\hline Controle & $33,8 \mathrm{ab}$ & $32,2 a$ & $32,5 a$ & $30,6 a b$ & $25,4 a$ & $34,5 a$ & 31,5 & & \\
\hline VitE -MM & $27,0 \mathrm{~b}$ & $31,7 a b$ & $31,6 a b$ & $23,8 b b$ & $29,5 a b$ & $31,3 a b$ & 29,1 & 12,7 & 31 a 38,5 \\
\hline VitE -BP & $30,1 a b$ & $34,0 a b$ & $29,9 a b$ & $35,2 a$ & $31,2 a b$ & $33,9 a b$ & 32,4 & & \\
\hline
\end{tabular}

Médias seguidas de letras iguais na coluna, em cada semana, não diferem entre si pelo teste de Tukey $(p<0,05)$ *NAVARRO e PACHALY (1994).

Tabela 8: Valores médios de leucócitos, linfócitos, eosinófilos e basófilos em potros nascidos das éguas das raças Mangalarga Marchador e Bretão Postier cujas dietas foram suplementadas com vitamina $\mathrm{E}$

\begin{tabular}{|c|c|c|c|c|c|}
\hline \multirow{2}{*}{ Variáveis } & \multicolumn{3}{|c|}{ Tratamentos } & \multirow{2}{*}{$\begin{array}{l}\text { CV } \\
(\%)\end{array}$} & \multirow{2}{*}{$\begin{array}{l}\text { Valores } \\
\text { normais* }\end{array}$} \\
\hline & $\begin{array}{c}\text { Controle } \\
\text { MM }\end{array}$ & $\begin{array}{l}\text { Vit E } \\
\text { MM }\end{array}$ & $\begin{array}{l}\text { Vit E } \\
\text { BP }\end{array}$ & & \\
\hline \multicolumn{6}{|c|}{ Leucometria } \\
\hline $\mathrm{LEU} / \mu \mathrm{L}$ & $9410,4 \mathrm{~b}$ & $11314,5 \mathrm{a}$ & $11472,5 \mathrm{a}$ & 31,6 & $6000 \mathrm{a} 12000$ \\
\hline $\operatorname{LIN}(\mu \mathrm{L})$ & $2058,4 \mathrm{~b}$ & $3479,0 \mathrm{a}$ & $2683,9 a b$ & 36,2 & 1500 a 7700 \\
\hline EOS $(\mu \mathrm{L})$ & $125,1 \mathrm{a}$ & $40,4 \mathrm{a}$ & $98,6 \mathrm{a}$ & 152,6 & 0 a 1000 \\
\hline BAS $(\mu \mathrm{L})$ & $79,1 \mathrm{a}$ & $0 \mathrm{~b}$ & $62,4 a b$ & 263,6 & Raros \\
\hline
\end{tabular}

LEU = leucócitos; LIN = linfócitos; EOS = eosinófilos; BAS = basófilos Médias seguidas de letras iguais na linha, para cada variável, não diferem entre si pelo teste de Tukey $(p<0,05)$. *NAVARRO e PACHALY (1994).

Tabela 9: Médias e equações de regressão (ER) da leucometria em função da idade dos potros nascidos das éguas das raças Mangalarga Marchador e Bretão Postier cujas dietas foram suplementadas com vitamina $\mathrm{E}$

\begin{tabular}{|c|c|c|c|c|c|c|c|c|c|}
\hline \multirow{2}{*}{ Variáveis } & \multicolumn{6}{|c|}{ Tempo (semanas) } & \multirow{2}{*}{ ER } & \multirow{2}{*}{$\begin{array}{l}\text { CV } \\
(\%)\end{array}$} & \multirow{2}{*}{$\begin{array}{l}\text { Valores } \\
\text { normais* }\end{array}$} \\
\hline & 1 & 3 & 5 & 7 & 9 & 11 & & & \\
\hline \multicolumn{10}{|c|}{ Leucograma } \\
\hline $\mathrm{LEU} / \mu \mathrm{L}$ & 6153,3 & 7058,3 & 14804,2 & 13083,3 & 10820,8 & 12475,0 & 1 & 31,6 & $\begin{array}{l}6000 \mathrm{a} \\
12000\end{array}$ \\
\hline $\operatorname{LIN}(\mu \mathrm{L})$ & 1509,1 & 1916,5 & 2855,4 & 3104,0 & 3175,1 & 3882,7 & 2 & 36,2 & 1500 a 7700 \\
\hline $\operatorname{NEU}(\mu \mathrm{L})$ & 3538,6 & 3840,7 & 9994,4 & 7974,6 & 6284,5 & 7237,8 & 3 & 36,7 & 2300 a 8500 \\
\hline $\operatorname{MON}(\mu \mathrm{L})$ & 912,8 & 1078,7 & 1710,2 & 1866,3 & 1222,2 & 1305,5 & 4 & 55,1 & 0 a 1000 \\
\hline
\end{tabular}

${ }^{1} \mathrm{v}=66,1+1,17 X, r^{2}=18,6(p<0,01) ;{ }^{2} v=11,5+4,54 x, r^{2}=30,1(p<0,01) ;{ }^{3} v=40,9+6,80 X, r^{2}=11,7(p<0,01) ;{ }^{4} v=10,9+7,28$ $X, r^{2}=11,4(p<0,01)$, onde $X$ significa semanas.

LEU = leucócitos; LIN= linfócitos; NEU = neutrófilos; MON = monócitos

*NAVARRO e PACHALY (1994). 
respectivamente, sugerindo uma resposta leucocitária mais intensa para os potros filhos de éguas suplementadas com vitamina $\mathrm{E}$.

Os valores médios dos leucócitos totais, linfócitos, neutrófilos e monócitos em função da idade dos potros nascidos das éguas das raças Mangalarga Marchador e Bretão Postier cujas dietas foram suplementadas com vitamina $E$ podem ser observados na Tabela 9. Observou-se efeito significativo da idade dos potros, expressas em semanas, nos valores médios dos leucócitos, linfócitos, neutrófilos e monócitos. Os resultados do leucograma sugerem um aumento de células de defesa e fagocitária, com aumento dos valores médios dos leucócitos e linfócitos dos potros nascidos das éguas das raças Mangalarga Marchador e Bretão Postier cujas dietas foram suplementadas com vitamina $E$. Os valores médios

\section{Referências}

AFZAL, M.; TENGERGY, R.P.; ELLIS, R.P. KIMBERLING, C.V.; MORRIS, C.J. Protection of rams against epididymitis by a Brucella ovis vitamin $\mathrm{E}$ adjuvant vaccine. Vet. Immunol. Immunopath., v. 7, p. 293-304, 1984.

AMBWAT,H.K.; MALHOTRA, D.V.; KUMAR, S.; DHAR, S. Erythrocyte associated haemato-biochemical changes in Babesia equi infection experimentally produced in donkeys. Vet. Parasit., v. 85, p. 319-324, 1999.

BEKYAROVA, G.; YANKOVA, T.; KOZAREV,I.; YANKOV, D. Reduced erythrocyte deformability related to activated lipid peroxidation during the early postburn period. Burns, v. 22, p. 291-294, 1996.

BÖSE, R.; JORGENSEN, W.K.; DALGLIESH, R.J.;FRIEDHOFF, K.T.; DE VOS, A.J. Current state and future trends in the diagnosis of babesiosis. Vet. Parasit., v. 57, p. 61-74, 1995.

BOTTEON, P.T.L. Aspectos clínicos e epidemiológicos da babesiose: desenvolvimento de um ELISA indireto para diagnóstico de Babesia equi (Laveran, 1901). 2003. 57 p. Tese (Doutorado em Ciências Veterinárias) - Instituto de Veterinária, Universidade Federal Rural do Rio de Janeiro, Rio de Janeiro.

COLES, E.H. Veterinary Clinical Pathology. $2^{\text {nd }}$ edition. W.B. Saunders Company, 1974,615p.

CRANDELL, K. Vitamin requirements in the horse. In: PAGAN, J. (ed.). Advances in Equine Nutrition II. CD-ROM. Kentucky, USA: KER, 2000. p. 305-315.

CUNHA, C.W.; SILVA, S.S.; OSÓRIO, B.L.; DUTRA, C.L Alterações hematológicas em eqüinos experimentalmente infectados com Babesia equi. Ciência Rural, v. 28, n. 2, p. 283-286, 1998.

DE WAAL, D.T. Equine Piroplasmosis: a review. Brit. Vet. J., v.148, p. 6-13, 1992.

FRAPE, D. Equine Nutrition and Feeding. $2^{\text {nd }}$ edition, Blackwell Science Ltd, 1998, $564 \mathrm{p}$.

HOFFMAN, R.M., MORGAN, K.L., LYNCH, M.P. Dietary vitamin and supplemented in the periparturient period influences immunoglobulins in equine colostrum and passive transfer in foals. In: EQUINE NUTRITION AND PHYSIOLOGY SYMPOSIUM, 16., 1999, Raleigh, North Caroline. Proceedings... ENPS: Raleigh, 1999. p.127-128.

JEFFCOTT, L.B. Passive immunity and its transfer with special reference to the horse. Biol. Rev., v. 47, p. 439-464, 1972.

LE BLANC, M.M.;MC LAURIN, B.I.; BOSWELL, R. Relationships among serum immunoglobulin concentration in foals, colostral specific gravity, and colostral immunoglobulin concentration. J. Am. Vet. Med. Ass., v. 189, n. 1, p. 57-60, 1986. dos monócitos estão acima dos valores normais sugerindo uma monocitose no decorrer do aumento da idade dos potros. Segundo Rudolph et al. (1975), após uma infecção aguda por $T$. equi, ocorre um aumento dos níveis de fibrinogênio plasmático e monocitose acompanhando a parasitemia.

\section{Conclusões}

A suplementação dietética de vitamina $E$ na dose de $80 \mathrm{mg}$ para cada $100 \mathrm{~kg}$ de peso vivo pareceu não ter sido suficiente para modular a resposta imune nas éguas. Entretanto, houve predominância de leucocitose e linfocitose, sem diminuição do volume globular médio, nos potros nascidos de éguas das raças Mangalarga Marchador e Bretão Postier alimentadas com dietas suplementadas com vitamina $\mathrm{E}$.

McDOWELL, L.R. Vitamins in Animal and Human Nutrition. Ed. Academic Press, Inc., 1989. p. 157-216.

MEO-SCOTONI, C.M.; MACHADO NETO, R. Transferência de imunidade passiva em eqüinos: características imunológicas do processo de formação do colostro. Rev. Soc. Brás. Zoot., v. 21, p. 200-204, 1992.

MURASE, T., UEDA, T.; YAMATO, O.; TAJIMA, M.; MAEDE,Y. Oxidative damage and enhanced erythrophagocytosis in canine erythrocytes infected with Babesia gibsoni. J. Vet. Med. Sci., v. 58, p. 259-261, 1996.

NAVARRO, C.E.K.; PACHALY, J.R. Manual de Hematologia Veterinária. Ed. Varela, 1994, $169 \mathrm{p}$.

OTSUKA, Y.; YAMASAKY, M.; YAMATO, O.; MAEDE, Y. The effect of macrophages on the erythrocyte oxydative damage and the pathogenesis of anemia in Babesia gibsoni-infected dogs with low parasitemia. J. Vet. Med. Sci., v. 64, p. 221-226, 2002.

PFEIFER BARBOSA, I.; BÖSE, R.; PEYMANN, B. FRIEDHOFF, K.T. Epidemiological aspects of equine babesiosis in a herd of horses in Brazil. Vet. Parasit., v. 2, n. 58, p. 1-8, 1995.

PORTZ, C. ; ALMEIDA, F. Q. ; MASSARD, C.L. ; BOTTEON, P.T.L. Avaliação da vitamina $E$ como imunomodulador e infecção intra-uterina por Theileria equi em potros. Parasit. Latinoam., v. 62, p. 16-22, 2007. PORTZ, C.; LARANJEIRA, P.V.E.H.; BOTTEON, P.T.L.; SANTOS, T.M.; GIACOMOLLI, E.A.; ALMEIDA, F.Q. Influência dos locais de coleta de sangue e do exercício no diagnóstico da babesiose eqüina. In: Congresso Brasileiro de Parasitologia,12., Rio de Janeiro. Anais... CBPA: Rio de Janeiro. CD-ROM, 2002.

RIBEIRO, M.F.B.; SAITO, J. F.; PIMENTEL, P. V. Babesiose eqüina I Primo Infecção de potros em áreas endêmicas. Arq. Bras. Med. Vet. Zootec, v. 47, n. 5, p. 641-647, 1995.

ROUSE, B.T.; INGRAM, D.G. The total protein and immunoglobulin profile of equine colostrum and milk. Immunology, v. 19, p. 901-907, 1970.

RUDOLPH, W.; CORREA, J.; ZURITA, L.; MANLEY, W. Equine piroplasmosis: leukocit response to Babesia equi (Laveran, 1910) infection in Chile. Brit. Vet. J., v. 131, p. 601-609, 1975.

SCHEIN, E. Equine babesiosis. In: RISTIC, M. Babesiosis of domestic animals and man. CRC. Boca Raton, Flórida, 1988. p. 197-208.

UNIVERSIDADE FEDERAL DE VIÇOSA. 2000. SAEG-Sistema de Análises Estatísticas e Genética. Viçosa: Universidade Federal de Viçosa, Manual do Usuário, 138 p. (versão 8.0). 